Caligrama, Belo Horizonte, v. 22, n. 2, p. 83-101, 2017

\title{
A presença de latinismos na redação acadêmica: análise de elementos de citação a partir da norma 10520
}

\author{
The presence of latinisms in the academic writing: \\ analysis of citation elements from standard 10520
}

Thiago Soares de Oliveira

Instituto Federal Fluminense, Campos dos Goytacazes, Rio de Janeiro / Brasil so.thiago@hotmail.com

Resumo: Considerando as diversas orientações constantes na NBR 10520 (ABNT, 2002), que regulamenta as formas de citação em documentos, este trabalho tem o objetivo de demonstrar a relevância dos latinismos existentes na metodologia científica da língua portuguesa - uma das diversas línguas românicas originadas do latim -, a partir da análise do léxico latino mormente empregado como elementos de citação em textos acadêmicos. Para tanto, utiliza-se a base gramatical da língua latina a fim de dar conta da investigação terminológica proposta, tudo em consonância com o método analítico, que visa a explorar não só o todo significativo da expressão, mas também as suas partes constituintes. Ao fim, concluise que o léxico latino, quando utilizado em citações em textos de cunho acadêmico, além de funcional e preciso, acaba por denotar, em alguns casos, economia linguística, evitando a repetição de referências.

Palavras-chave: terminologia; latinismo; redação acadêmica.

Abstract: Contemplating various orientations in ABNT 10520:2002, which regulates citation forms in documents, this paper aims to demonstrate how the applicability of the Latins Existing in scientific methodology of Portuguese language works, which is one of the Romance languages originated from Latin, starting from the analysis of Latin lexicon especially used as citation elements in academic works. Therefore, Latin language grammatical basis is used to handle the 
terminological investigation proposed, in accordance whith analytical method, which aims to explore not only the meaningful whole of the Latin expression but its integral parts. Finally, it is concluded that Latin lexicon, when used in academic texts citations, besides usable and clear, denotes, in some cases, linguistic economy, avoiding reference repetition. Keywords: terminology; Latinism; academic writing.

Recebido em: 3 de julho de 2017. Aprovado em: 1ํ de agosto de 2017.

\section{Considerações iniciais}

Dada a formalidade que normalmente reveste os textos de caráter acadêmico, bem como a necessidade de dar aos autores os créditos a suas ideias e aos trechos transcritos de suas obras consultadas e utilizadas na escrita acadêmica, a norma 10520:2002, da Associação Brasileira de Normas Técnicas (ABNT), determina o uso de vocábulos e expressões que garantem a padronização da estruturação das referências internas em trabalhos que se valham de citações, diretas ou indiretas, além de citação de citação. Dessa forma, tal norma é relevante na seara da metodologia científica que orienta a escrita de trabalhos acadêmicos em língua portuguesa.

Como muitos termos recomendados pela norma são, na verdade, expressões latinas cuja utilização depende de sua propriedade de referenciar e estruturar a escrita formal, este artigo tem o escopo de demonstrar como são aplicados os latinismos existentes nas diretrizes metodológicas representadas pela NBR 10520 (ABNT, 2002) da língua portuguesa com base na análise do léxico latino empregado na redação acadêmica. Para dar conta do objetivo traçado, recorrer-se-á aos fundamentos gramaticais latinos com o intuito de analisar o latinismo sob um duplo viés: o valor do todo significativo e suas partes constituintes. Adota-se o método analítico como melhor forma de desenvolver o estudo teórico que ora se propõe do corpus presente na NBR 10520.

Quanto à estrutura, este trabalho se subdivide em duas seções: a primeira, que visa a uma abordagem geral acerca da escrita acadêmica, apontando para a necessidade de determinados padrões de citação nesse tipo de redação; a segunda, que pretende, por meio da análise, explorar 
o significado da nomenclatura latina recomendada pela NBR 10520 (ABNT, 2002). Considerando a importância do respeito a determinados padrões em textos sujeitos aos ditames da redação acadêmica, justificase este artigo em razão da tentativa de compreender o porquê do uso do latinismo nesse tipo de escrita, embora existam termos e expressões equivalentes em língua portuguesa.

Assim sendo, vislumbra-se aqui uma forma de colaborar para a compreensão teórica do léxico latino utilizado com fins terminológicos, demonstrando a razão da utilização da língua clássica em detrimento da língua românica moderna: o português.

\section{Noções gerais sobre a relevância da citação de autores e obras na escrita acadêmica}

Uma das maiores preocupações correntes na escrita acadêmica diz respeito à correta referenciação do autor no texto. Isso ocorre porque os créditos às ideias e às transcrições devem ser atribuídos aos escritores das obras citadas ou mencionadas sob pena de que não se preserve o direito autoral do indivíduo que se dispôs a pesquisar e a tecer, na modalidade escrita, suas observações, interpretações e percepções a respeito do tema que desenvolve. Além do mais, a referência permite ao leitor checar na fonte se o autor interpretou e registrou corretamente o texto ou a ideia originais.

Segundo Moraes (2004, p. 95), apesar de a Lei de Direitos Autorais (LDA) não mencionar nem conceituar o que é plágio, ${ }^{1}$ deixando tal tarefa a cargo da doutrina, "plágio é a imitação fraudulenta de uma obra, protegida pela lei autoral, ocorrendo verdadeiro atentado aos direitos morais do autor" (MORAES, 2004, p.95). Ainda que, muitas vezes, o plágio seja consciente e propositado, nem sempre o indivíduo que se inicia na redação acadêmica conhece os mecanismos existentes (elencados pela NBR 10520) para evitar esse tipo de prática prejudicial à contribuição científica deixada pelos autores dos diversos campos de pesquisa.

Nesse sentido, Moraes (2004) explica que, na verdade, não existe plágio de ideias, por não serem elas objeto de proteção legal. Assim, as ideias pertencem à coletividade enquanto a forma dada a elas é sempre individual. O cuidado recai, no entanto, sobre a ideia

\footnotetext{
${ }^{1}$ É importante registrar que patentes, as quais também são ideias, podem ser plagiadas.
} 
materializada, ou seja, quando a ideia passa a ter traços característicos do autor. Aprofundando mais um pouco no assunto, a Lei 9.610/1998, que altera, atualiza e consolida a legislação sobre direitos autorais e dá outras providências, afirma não constituir ofensa aos direitos autorais a citação, em diversos meios de comunicação, de passagens de qualquer obra, para fins de estudo, crítica ou polêmica, desde que sejam indicados o nome do autor e a origem da obra, sendo livres as paráfrases e as paródias que não forem reproduções da obra original, implicando-lhe descrédito.

Isso significa que, referenciada e citada de forma correta, não há irregularidade na menção ou alusão à obra de autores outros, já que, dessa forma, fica assegurado o crédito devido. É por isso mesmo que a NBR 10520 (ABNT, 2002) especifica as características exigíveis para a apresentação de citação em documentos, dispondo sobre as seguintes definições: citação, citação de citação, citação direta, citação indireta, notas de referência, notas de rodapé e notas explicativas. Não cabe, pois, ao escritor acadêmico confeccionar um texto sem a devida referenciação, quando necessária for, especialmente porque a ABNT, facilitando o acesso às fontes primárias, ${ }^{2}$ padroniza a redação da forma de entrada daquela, desempenhando uma função não apenas normativa, mas também social.

Considerando que pesquisa é "a atividade básica da ciência na sua indagação e construção da realidade" e que "ela alimenta a atividade de ensino e a atualiza frente à realidade do mundo" (MINAYO, 2009, p. 16), um importante procedimento da pesquisa científica é justamente a investigação do assunto a ser tratado, garantindo que a temática não tenha sido anteriormente abordada sob a mesma ótica ou perspectiva pretendida no momento da redação acadêmica. De qualquer forma, já tendo sido abordada, isso não se torna óbice para a utilização de obras pioneiras na pesquisa pretendida, já que existem vários mecanismos que permitem ao autor-pesquisador a citação correta das fontes pesquisadas. Aliás, a investigação acerca da existência de publicações anteriores em relação à temática a ser desenvolvida é item relevante para o início de

\footnotetext{
${ }^{2}$ Segundo Lakatos e Marconi (2007, p. 161), as fontes primárias dizem respeito a “dados históricos, bibliográficos e estatísticos; informações, pesquisas e material cartográfico; arquivos oficiais e particulares; registros em geral; documentação pessoal (diários, memórias, autobiografias); correspondência pública ou privada etc.”. Já as fontes secundárias consubstanciam-se nos documentos da "imprensa em geral e obras literárias".
} 
uma escrita científica, uma vez que proporciona a verificação do estado da arte do assunto, mesmo que sob ângulo distinto do que se deseja discutir.

Nesse ponto, percebe-se a necessidade de padronização da citação ${ }^{3}$ na escrita acadêmica não só como forma de proteção aos direitos dos autores, mas também como meio de organizar a qualidade do trabalho científico no que concerne ao seu conteúdo, aos fins e à substância, conforme aponta Demo (1991). A propósito, a padronização da escrita acadêmica em geral e das entradas de citação são itens essenciais à linguagem utilizada em textos científicos, pois, além de primarem pela correção e pela precisão, pela coerência na argumentação, pela clareza na exposição das ideias, pela objetividade e pela concisão, levam em consideração a fidelidade das fontes citadas. Esta costuma ser alcançada por meio da utilização de um vocabulário técnico, uma vez que "a linguagem científica serve-se do vocabulário comum, utilizado com clareza e concisão, mas cada ramo da ciência possui uma terminologia técnica própria que deve ser observada" (PÁDUA, 1996, p. 82).

Partindo da citação de Pádua (1996), pode-se depreender, por analogia, que a seara da metodologia científica também dispõe de terminologias próprias para garantir a boa condução da pesquisa, inclusive no que se refere à citação de obras e autores. À guisa de exemplo, no texto dissertativo de caráter científico, a fundamentação teórica pode se valer de vários elementos para aumentar o poder de persuasão, como é o caso do argumento de autoridade, que se apoia "no saber notório de uma autoridade reconhecida num certo domínio do conhecimento. É um modo de trazer para o enunciado o peso e a credibilidade da autoridade citada" (FIORIN; SAVIOLI, 2007, p. 311). Nesse caso, ao embasar um argumento a partir de trechos da obra de um autor, este deve ser referenciado, não importando se for citado direta ou indiretamente ou por meio da obra de outro estudioso (citação de citação), a referência sempre será necessária. Como bem explica Tozoni-Reis (2010), as normas surgiram

Para que as descobertas científicas pudessem ser conhecidas, comunicadas, criticadas e avaliadas por cientistas de diferentes partes do mundo. Nesse sentido, mesmo correndo risco de criar mecanismos controladores da criatividade na produção

\footnotetext{
${ }^{3}$ É importante frisar também que a identificação da citação permite ao leitor verificar o que é a contribuição original do autor de um texto e o que é mera reprodução de ideia prévia.
} 
de conhecimentos, as normas de apresentação de trabalhos científicos têm a função de facilitar a comunicação de resultados dos estudos investigativos, oferecendo-os de forma mais acessível e democrática à crítica de nossos pares, condição primordial do avanço da ciência. (TOZONI-REIS, 2010, p. 120)

Partindo da citação de Tozoni-Reis (2010), especialmente da necessidade de oferecer aos pares uma forma mais acessível e democrática de crítica aos trabalhos produzidos, de modo que se possa promover o avanço da ciência, é que se percebe a relevância da correta referenciação das obras utilizadas em um trabalho de caráter científico, bem como da atribuição do crédito das ideias e das transcrições a seus respectivos autores. Quando o indivíduo escreve um texto acadêmico, deve ter em vista que, ao citar a obra de determinado autor, ele está, na verdade, aderindo a um posicionamento para corroborar os fundamentos e os resultados de sua pesquisa. Então, a citação acaba por fornecer ao leitor do trabalho científico o alinhamento teórico do estudo, inserindo-o em uma área específica do conhecimento.

Nessa linha de raciocínio, há, com efeito, uma necessidade de padronização de citações na escrita acadêmica, o que é promovido pela norma 10520 (ABNT, 2002), cujas principais recomendações são as seguintes:

5. Nas citações, as chamadas pelo sobrenome do autor, pela instituição responsável ou título incluído na sentença devem ser em letras maiúsculas e minúsculas e, quando estiverem entre parênteses, devem ser em letras maiúsculas. 5.1. Especificar no texto a(s) página(s), volume(s), tomo(s) ou seção(ões) da fonte consultada, nas citações diretas. Este(s) deve(m) seguir a data, separado(s) por vírgula e precedido(s) pelo termo, que o(s) caracteriza, de forma abreviada. Nas citações indiretas, a indicação da(s) página(s) consultada(s) é opcional. 5.2. As citações diretas, no texto, de até três linhas, devem estar contidas entre aspas duplas. As aspas simples são utilizadas para indicar citação no interior da citação. 5.3. As citações diretas, no texto, com mais de três linhas, devem ser destacadas com recuo de $4 \mathrm{~cm}$ da margem esquerda, com letra menor que a do texto utilizado e sem as aspas. No caso de documentos datilografados, deve-se observar apenas o recuo (ABNT, 2002, p. 2). 
Embora NBR 10520 (ABNT, 2002) recomende formas de entrada para citações diretas e indiretas na sua parte geral, ela não se furta a fazer menção ao funcionamento da citação da citação no texto científico, o que ocorre no decorrer do documento à medida que são introduzidas as diversas expressões latinas utilizadas terminologicamente como forma de referência. Dessa forma, vale explicar as três principais formas de citação que se devem conhecer ao redigir um texto acadêmico: a citação direta, a citação indireta e a citação da citação. Segundo Lakatos e Marconi, a citação direta consiste

na transcrição literal das palavras do autor, respeitando todas as suas características. Devem ser transcritas sempre entre aspas e seguidas pelo sobrenome do autor, data de publicação e páginas da fonte em que foram retiradas, separados por vírgula e entre parênteses (LAKATOS; MARCONI, 2007, p. 288).

Trata-se, em outras palavras, de uma referência completa, já que se reproduzem com fidelidade as palavras do autor citado, ainda que haja inadequações e inconsistências decorrentes da escrita autoral. Nesse caso, recomenda-se a utilização do termo latino sic ("assim", "dessa forma", em latim), ao fim do trecho transcrito, como forma de garantir que a reprodução de parte da obra se deu ipsis litteris, isto é, letra por letra. Na prática, contudo, não ocorre assim, já que as aspas já indicam que se trata de transcrição literal. O termo sic é usado, pois, para assinalar que um elemento que pode parecer ao leitor erro de transcrição estava assim (por isso, sic) no original.

Já a citação indireta são ideias ou informações extraídas de outros autores, mas escritas com as palavras do indivíduo que redige o texto acadêmico. Normalmente, essa citação ocorre em forma de paráfrase e sempre deve mencionar o texto original (LAVILLE; DIONNE, 1999). Consoante a Tozoni-Reis (2010, p.126) sobre a citação indireta, "fazer referência a um autor no texto significa apresentar suas ideias segundo a interpretação do pesquisador". Sendo assim, se tratando de reprodução de noções que adquiriram forma em razão das peculiaridades dos autores citados, é imprescindível a referenciação da ideia utilizada com o intuito de dar validade à pesquisa por meio do apoio em estudos próximos à temática em questão. Para esse tipo de citação, a NBR 10520 (ABNT, 2002) determina que a entrada se dê pelo sobrenome do autor seguido do ano da obra. 
A citação da citação, por sua vez, é utilizada "quando se transcrevem palavras textuais ou conceitos de autor sendo ditos por um segundo autor da fonte que se está consultando diretamente." (LAKATOS; MARCONI, 2007, p. 290). Essa espécie de citação pode ser verificada quando se cita um autor que, por seu turno, cita outro em seu texto. Tratase de uma citação dentro de outra. Nesse caso, a expressão latina apud é utilizada como forma de demonstrar que se trata de citação de citação. A citação da citação, assim como as demais, "são feitas para apoiar uma hipótese, sustentar uma idéia ou ilustrar o raciocínio por meio de menções de trechos na bibliografia consultada" (MORESI, 2003, p. 52).

Por fim, vale o registro de que, "embora sejam importantes para fomentar o necessário diálogo entre o pesquisador e outros pesquisadores de assuntos e temas correlatos, o recurso da citação dever ser usado somente quando for muito pertinente à discussão empreendida no texto" (TOZONI-REIS, 2010, p. 124). Isso quer dizer que o excesso de citações pode obnubilar a presença do redator do texto acadêmico. Apesar de ser relevante mencionar autoridades no assunto pesquisado, o cuidado com a citação deve ocorrer no sentido de evitar o apagamento autoral em razão da abundância de ideias e trechos de outrem.

\section{Análise de latinismos utilizados como terminologia da metodologia científica}

O corpus principal selecionado para análise neste trabalho é composto dos latinismos utilizados como terminologia presentes na NBR 10520 (ABNT, 2002). Os exemplos que ilustram a explicação de cada item terminológico são retirados propositadamente de escritos acadêmicos como artigos científicos, dissertações e teses, tendo em vista a necessidade de comprovar o uso nesse tipo de redação. Todas as obras utilizadas nesses contextos são posteriores a 2002, a fim de que se possa pressupor o respeito à NBR 10520. Passando, pois, ao exame dos termos e expressões latinos correntes durante o processo de citação de autores, eis os elementos encontrados na norma em questão:

\section{a) idem (ou id.)}

Trata-se de um pronome empregado "para mostrar as pessoas ou objetos" (FARIA, 1958, p. 134). Faria (1958) considera tal item gramatical como um pronome de identidade que pode ser concebido como 
"o precisamente... que" ou "aquele mesmo... que". Como a utilização de idem no texto acadêmico visa evitar a repetição de referências na mesma página ou folha da citação a que se referem (ABNT, 2002), adota-se a tradução proposta por Almeida (1992): "ele mesmo", "ela mesma" etc.

Aliás, é importante observar que, mesmo se tratando de um pronome declinável em latim, a forma idem não sofre flexão de caso na referenciação científica, já que a alusão se dá em relação a uma citação completa anterior. Não há, pois, a necessidade de mudança na estrutura escrita da palavra porque não há, no caso da citação, relação sintática a ser marcada pela desinência de flexão casual. Eis que idem surge como genuína terminologia na metodologia científica, dado o seu caráter técnico de uso. Contudo, fosse esse item flexionável pelo emprego em situações diversas, a sua forma sofreria modificações a depender do gênero, do número e do caso, o que se representa no Quadro 1, que segue:

Quadro 1 - Declinação de idem, eadem, idem

\begin{tabular}{|l|l|l|}
\hline \multicolumn{2}{|c|}{ Declinação de idem, eadem, idem } \\
\hline \multicolumn{1}{|c|}{ Casos latinos } & \multicolumn{1}{|c|}{ Singular } & \multicolumn{1}{c|}{ Plural } \\
\hline & Masculino / Feminino / Neutro & Masculino / Feminino / Neutro \\
\hline Nominativo & Idem, eadem, idem & Iidem, eaedem, eadem \\
\hline Genitivo & Eiusdem & Eorundem, earundem, eorundem \\
\hline Dativo & Eidem & Iisdem ou eisdem \\
\hline Ablativo & Eodem, eadem, eodem & Iisdem ou eisdem \\
\hline Acusativo & Eundem, eandem, idem & Eosdem, easdem, eadem \\
\hline
\end{tabular}

Fonte: Almeida (1992)

Conforme o Quadro 1, percebe-se que a forma idem é, na verdade, masculina, ${ }^{4}$ sendo esta a adotada para a referenciação nos textos acadêmicos. $\mathrm{O}$ fato de, em português, não ser possível a declinação ${ }^{5} \mathrm{de}$

\footnotetext{
${ }^{4}$ Poderia ser também neutra, como nominativo ou acusativo singular de "i" inicial breve, mas não é o caso aqui, já que neutro em geral não aponta para "pessoa", ser humano em latim.

${ }^{5} \mathrm{Na}$ verdade, a declinação do item lexical, por já estar incorporado ao uso do português, é impossível, pois não existe mecanismo declinatório nessa língua moderna.
} 
tal pronome, até porque não há relação sintática expressa na situação de citação, facilita o uso dessa terminologia e justifica sua permanência para tal finalidade. Segundo Almeida (1992, p. 163), "é muito usado em latim o demonstrativo is, ea, id seguido da terminação dem, terminação que reforça o demonstrativo e se traduz por mesmo".

À guisa de exemplo, eis um trecho transcrito do artigo científico de Monteagudo (2012, p. 59):

Quem mais pronta e argumentadamente deu réplica a Lapa foi o seu grande amigo, o intelectual galego Ramón Piñeiro, em artigo publicado na revista Grial. Em apurado resumo, este sustém:

'[...] Se calhar, muitos portugueses refugarão, mesmo com escândalo, esta afirmação. Contudo, resultara-lhes mais fácil negar o fato do que impedi-lo... Não é o português moderno o herdeiro literário único do galego-português originário, mas há três herdeiros, três continuadores: o galego, o português e o brasileiro'. (PIÑEIRO, 1974, p. 278)

Ramón Piñeiro defende a posição tradicional do galeguismo contemporâneo de procurar o apoio no português para a modernização do galego e de fomentar uma aproximação decidida da cultura galega às culturas de expressão portuguesa:

'a política a seguir na fixação do galego culto deve se orientar decididamente à consolidação de tudo o que houver de comum no galego e no português, e na incorporação do vocabulário técnico também devemos tender à maior identidade das duas línguas irmãs. [...] Nesta linha de achegamento, a atitude galega será sempre aberta e entusiasta'. (idem, p. 279)

No trecho acima, pode-se notar a utilização de idem na segunda citação por haver referência a Piñeiro, autor já mencionado na primeira citação. Nesse caso, a terminologia idem foi empregada com o propósito de evitar a repetição do sobrenome do autor e do ano de sua obra, já que ambos se encontram na mesma página no artigo. Logo, a terminologia mostra-se bastante funcional na medida em que respeita os ditames da NBR 10520 (ABNT, 2002). Por se tratar de termo latino, é preciso perceber que idem encontra-se em itálico. 


\section{b) ibidem (ou ibid.)}

O termo ibidem é um advérbio latino (palavra indeclinável) que significa "no mesmo lugar", "aí mesmo", entre outras possibilidades de tradução (FARIA, 1992, p. 258). Segundo a norma NBR 10520 (ABNT, 2002), emprega-se com sentido de "na mesma obra", possivelmente devido ao valor locativo claramente expresso pelo vocábulo. No trecho abaixo, pertencente à obra de Monteagudo (2012, p. 29), pode-se perceber a intencionalidade de uso de ibidem: Porém, adverte de jeito muito explícito:

"Mas será achegamento desde o galego, não renunciando ao galego" (ibidem).

O excerto acima é parte complementar da sequência apresentada na explicação do termo idem. No exemplo sob análise, o termo locativo ibidem foi empregado considerando-se que a citação direta utilizada fora retirada da obra de autor já mencionado na mesma página; nesse caso, em parágrafo anterior, representado pela expressão idem, que, por sua vez, remete a Piñero (1974). O que se nota é que ibidem evitou a repetição de idem, termo de referência primeiramente empregado na referência a Piñero. Terminologia também grafada em itálico por se tratar de latinismo.

\section{c) opus citatum (ou op. cit.)}

O elementos constituintes da expressão opus citatum são opus, um substantivo do gênero neutro do segundo grupo da terceira declinação latina, ${ }^{6}$ sendo este grupo caracterizado pelas terminações -us, -en, - $m a$, $-o r,-u t,-u r,-e r,-o s$ e -as no nominativo singular, segundo Ribeiro e Simonetti (2014), seguido de citatum, particípio passado do verbo latino cito,-as,-are, -avi, -atum, que pode significar, entre outras acepções, citar, convocar, mencionar, de acordo com Faria (1992). Em português, equivale a "obra citada".

\footnotetext{
${ }^{6}$ Considerando a complexidade morfológica da terceira declinação latina, não se abordará o tema detalhadamente a fim de não fugir ao escopo deste trabalho, até porque as formas de nominativo singular correspondentes aos neutros do segundo grupo da terceira declinação podem ser várias. Dessa forma, o aporte teórico desta seção ateve-se à explicação simplificada proposta por Ribeiro e Simonetti (2014).
} 
Essa expressão faz alusão a uma obra já citada anteriormente na mesma página, evitando a repetição das referências, assim como idem. Eis um exemplo de emprego da expressão no trabalho de Aragão (2011, p. 7):

DIEGUES JR. Manuel. Etnias e culturas no Brasil. 5. ed. Rio de Janeiro: Civilização Brasileira; Brasília: INL, 1976, p. 99.

FREYRE, Gilberto. Casa grande e senzala. Rio de Janeiro: José Olympio, 1954. apud DIEGUES JR. M. op. cit. p. 99-100.

Os trechos acima foram retirados de duas notas bibliográficas subsequentes na obra de Aragão (2011). Na segunda nota, a autora fez uso de op. cit. a fim de evitar a repetição do nome do livro de Diegues Jr., Etnias e culturas no Brasil. Embora Aragão tenha se valido da terminologia em referência bibliográfica, e não em citação interna de autor, tal possibilidade existe e pode ser comprovada a partir de excerto transcrito da dissertação de mestrado de Silva (2009, p. 11):

Igualmente, Konrad Koerner (1996, p. 49) diz que o objeto de estudo da Historiografia Lingüística são "as idéias sobre a linguagem e proposições para sua descrição e explicação". Além disso, esse autor diz que "as teorias lingüísticas não se desenvolvem em total isolamento do clima intelectual geral do período ou das atitudes particulares mantidas pela sociedade que promoveu a atividade científica" (op. cit., p. 57).

Na dissertação de Silva (2009), cujo trecho foi transcrito acima, a utilização de op. cit. tem a mesma finalidade da de Aragão (2011). Entretanto, no caso em análise, a equivalência entre a terminologia e o autor e o ano dá-se dentro do mesmo parágrafo. Dessa forma, a segunda citação direta constante no trecho dissertativo também é atribuída a Konrad Korner (1996), havendo apenas a modificação da página da qual o trecho foi transcrito. Note-se a manutenção da terminologia em itálico por se tratar de um latinismo.

\section{d) passim (ou pass.)}

De uso mais restrito, passim é um advérbio latino cuja tradução recomendada por Faria (1992, p. 392) é "espalhando-se por aqui e por ali, daqui e dali, a cada passo", mas normalmente é traduzida por "aqui e lá". $\mathrm{O}$ uso dessa expressão locativa ocorre quando se quer indicar referências 
genéricas a diversas partes do texto sem a indicação das páginas, por se tratar de um compilado de citações. Normalmente o termo é utilizado em nota de referência que remete à citação em recuo, como se pode verificar no exemplo abaixo, a partir da obra de Leite (2011):

\section{LEITE, 2011, p. 95-123 passim}

A utilização da terminologia no exemplo acima faz referência a diversas páginas donde se retiraram ideias do autor, evitando, logo, a repetição dessas páginas. Assim sendo, a expressão passim é assaz abrangente, dando conta de múltiplas noções retiradas do texto de um autor citado (Leite, no caso acima). A título ilustrativo, da obra de Leite (2011) poderiam ter sido utilizadas ideias constantes nas páginas 95, 103, 108 e 120, por exemplo. Nesse caso, o uso de passim acaba por indicar uma referência genérica a várias partes do texto, sem que se identifiquem páginas determinadas. Normalmente, são indicadas as páginas inicial e final do trecho onde se encontram as informações citadas.

\section{e) loco citato (ou loc. cit. $)^{7}$}

A expressão loco citato, pela forma com é grafada, está declinada no ablativo $^{8}$ singular, visto que a palavra locus, $-i$ (enunciada ${ }^{9}$ no nominativo singular seguido do genitivo singular), além de estar grafada com a desinência representativa do ablativo singular (-o), designa a noção de lugar, equivalendo a "no lugar citado". A citato, por ser particípio passado do verbo cito,-as,-are,-aui,-atum, funcionando como um adjetivo do substantivo locus, concorda com este em gênero, número e caso, ou

\footnotetext{
${ }^{7}$ Para as expressões loco citato e sequentia são utilizados exemplos hipotéticos em razão do menor uso de tais terminologias em comparação com as demais já analisadas. ${ }^{8} \mathrm{O}$ ablativo é o caso latino clássico que representa a função sintática de adjunto adverbial, incluindo as circunstâncias de instrumento e de lugar, sendo esta também representada pelo caso locativo de forma indicial, já que tal caso apenas deixou alguns resquícios, não funcionando como categoria plena para a maioria das palavras em latim clássico.

${ }^{9}$ Para fins de identificação dos substantivos em latim, estes são enunciadas a partir de seu nominativo singular (caso que, normalmente, representa a função sintática de sujeito e de predicativo do sujeito), seguido do genitivo singular (caso distintivo que representa, via de regra, o adjunto adnominal restritivo).
} 
seja, citato encontra-se no masculino (gênero) singular (número) e no ablativo (caso). Eis um exemplo que ilustra o uso de tal expressão:

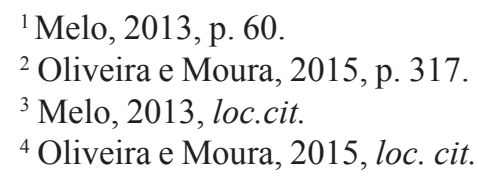

Analisando o exemplo acima, suposto a partir dos artigos de Melo (2013) e Oliveira e Moura (2015), percebe-se que a expressão loco citato é utilizada quando se pretende designar a mesma página de uma obra já citada anteriormente, quando há intercalação de notas. Assim como várias das outras terminologias analisadas, o uso de loco citato também tem o objetivo de evitar a repetição de item já mencionado anteriormente, nesse caso, a página. Note-se, porém, que a expressão tem um uso restrito à intercalação de notas, apresentando, pois, emprego distinto da expressão opus citatum. Se os autores Melo e Oliveira e Moura tivessem sido citados de forma não intercalada, a melhor terminologia ser utilizada seria opus citatum, que evitaria a repetição das obras já mencionadas anteriormente. Apesar de o exemplo configurar uma utilização terminológica em nota de rodapé, também é possível o emprego da expressão no corpo do texto, não havendo necessidade de que a obra citada esteja na referência imediatamente anterior, como explicado acima.

\section{f) sequentia (ou et seq.)}

A terminologia sequentia, normalmente significa "sequência", mas, considerando-se o uso de tal expressão e sua forma escrita, seria mais bem traduzida como "na sequência", já que o vocábulo encontra-se declinado no ablativo singular. A NBR 10520 (ABNT, 2002) traduz o termo como "seguinte ou que se segue". Eis um exemplo hipotético de uso a partir da obra de Avelar e Galves (2014):

${ }^{1}$ Avelar; Galves, 2014, p.242 et seq.

Como outro termo que configura economia linguística, o item latino é empregado com a função de evitar a menção de todas as páginas ou folhas consultadas na obra referenciada. No exemplo acima, notase que, na obra de Avelar e Galves (2014), a primeira página consulta é a 242 , não sendo mencionadas as demais, ou porque são diversas ou 
porque assim preferiu o redator. Ainda que o exemplo represente uma citação referenciada em nota, há a possibilidade de uso da terminologia latina no corpo do texto.

\section{g) apud}

O termo apud é uma preposição latina que pode significar, entre outras noções, "junto de", consoante ao que expõe Faria (1992). Em latim, as preposições geralmente figuram nas frases para, em conjunto com outros vocábulos, introduzir uma noção de circunstância, não sendo utilizadas com a mesma frequência da língua portuguesa, já que essa é uma língua analítica, enquanto aquele é um idioma sintético. Em poucas palavras, entende-se como língua sintética aquela que, por meio de desinências acopladas a nomes e verbos, dispensa o uso frequente de classes de palavras como numeral, preposição e alguns pronomes.

$\mathrm{Na}$ metodologia científica e na redação de textos de caráter acadêmico, apud, normalmente traduzida como "citado por" é utilizada na "menção de um documento ao qual você não teve acesso, mas que tomou conhecimento por citação em um outro trabalho" (MORESI, 2003, p. 53). Trata-se da citação de citação. Nesses casos, a termo apud é utilizado "quando se transcrevem palavras textuais ou conceitos de autor sendo ditos por um segundo autor da fonte que se está consultando" (LAKATOS; MARCONI, 2007, p. 290). Eis um exemplo transcrito da tese de doutorado de Rubio (2012, p. 30):

Assim Fernão de Oliveira analisa o emprego dos vocábulos na língua falada influenciados pela variação social, regional e etária no território português em 1536 :

'[...] E o velho, como tem o entender mais firme, com o que mais sabe, também suas falas são de peso, e as do mancebo, mais leves... saibamos que a primeira e principal virtude da língua é ser clara e que a possam entender, e para ser bem entendida há de ser a mais acostumada entre os melhores dela e os melhores da língua são os que mais leram e viram e viveram, continuando mais entre primores sisudos e assentados, e não amigos de muita mudança. (OLIVEIRA apud MATTOS E SILVA, 1988, p. 11)'.

Acima foram transcritos dois trechos da tese de Rubio (2012) na qual o autor menciona a análise de Fernão de Oliveira acerca do emprego 
de vocábulos da língua falada. Considerando a antiguidade da obra de Oliveira, Rubio (2012) teve de recorrer a Mattos e Silva para que tivesse acesso à citação. Assim, embora seja de Fernão de Oliveira o trecho transcrito em recuo, foi a partir de outro autor que se pôde recuperar a citação. Isso é bastante comum em se tratando de citação de excertos de obras antigas a que não mais se tem acesso com facilidade. $\mathrm{O}$ uso de apud, no caso em tela, é adequado à situação em que se insere. Vale, no entanto, ressaltar que, sendo possível, a citação de um autor deve se dar preferência pela consulta à obra original, tanto na citação direta quanto na indireta, mas especialmente nesta, já que a ideia original pode ter sofrido influência do pensamento do autor a que se recorre.

\section{Considerações finais}

Partindo da análise dos latinismos relativos à citação constantes na NBR 10520 (ABNT, 2002), percebeu-se que a maioria deles tem o escopo de evitar recorrência de referências, tornando a redação do texto científico menos repetitiva. Os elementos terminológicos têm a função precípua de padronizar e estruturar as citações direta e indireta, bem como a citação de citação.

Como se pôde notar, algumas terminologias são utilizadas de forma mais habitual, figurando em textos de caráter científico escritos após 2002, ano da edição da norma ABNT. Outras, no entanto, não são costumeiras, conquanto sejam claramente úteis na escrita acadêmica por força de organização textual e normalização da escrita. Tais nomenclaturas, como latinismos que são, grafam-se em itálico como forma de marcar que não se trata de uso de léxico originário da língua portuguesa, a despeito de já estar a ela incorporada.

As expressões, analisadas tanto em seus elementos constituintes como em seu todo significativo, resvalam certa credibilidade de uso que, normalmente, é atribuída a uma língua clássica, com baixa capacidade de mutação e com fins científicos, como se pode notar pelo uso na taxonomia de animais e plantas, por exemplo. Além disso, as terminologias despontam como forma de economia linguística típica das línguas na medida em que, mesmo utilizando menos palavras, abarca sentido amplo. Note-se que as terminologias latinas normalmente se valem de menos vocábulos do que sua correspondente tradução em português, já que, enquanto este idioma é analítico, aquela língua é considerada sintética. 
Ante o exposto, surgem como funcionais as terminologias elencadas na norma 10520 (ABNT, 2002), não só pela baixa mutabilidade da língua latina, idioma clássico do qual se originou o português, e pelo esforço de economia linguística, mas também porque tais expressões normalizam a escrita acadêmica, permitindo que seja entendida a qualquer tempo em razão de um padrão de redação.

\section{Referências}

ALMEIDA, N. M. de. Gramática Latina: curso único e completo. 24. ed. São Paulo: Saraiva, 1992.

ARAGÃO, M. do S. S. de. Africanismos no português do Brasil. Revista de Letras, Fortaleza, UFC, v. 30, n. 1/4, jan. 2010/dez. 2011, p. 7-16. Disponível em: < http://www.revistadeletras.ufc.br/Revista\%20de \%20 Letras\%20Vol.30\%20-\%201.4\%20-\%20jan.\%202012\%20.\%20dez.\%20 2011/r130art01_Africanismos_no_portugues_do_Brasil.pdf $>$. Acesso em: 1 jul. 2017.

AVELAR, J.; GALVES, C. O papel das línguas africanas na emergência da gramática do português brasileiro. Linguística, Asociación de Lingüística y Filología de América Latina, Montevideo, v. 30, n. 2, dez. 2014, p. 241-288. Disponível em: <http://www.scielo.edu.uy/pdf/ling/ v30n2/v30n2a10.pdf>. Acesso em: 3 jul. 2017.

ASSOCIAÇÃO BRASILEIRA DE NORMAS TÉCNICAS (ABNT). NBR 10520 Informação e documentação - Citações em documentos - Apresentação. Rio de Janeiro: ABNT, 2002. Disponível em: <http:// www.usjt.br/arq.urb/arquivos/nbr10520-original.pdf>. Acesso em: 29 jun. 2017.

BRASIL. Lei 9.610, de 19 de fevereiro de 1998. Altera, atualiza e consolida a legislação sobre direitos autorais e dá outras providências. Disponível em: <http://www.planalto.gov.br/ccivil_03/leis/L9610.htm>. Acesso em: 30 jun. 2017.

DEMO, P. Avaliação qualitativa. São Paulo: Cortez, 1991.

FARIA, E. Dicionário escolar latino-português. Revisão de Ruth Junqueira de Faria. 6. ed. Rio de Janeiro: FAE, 1992. 
FARIA, E. Gramática Superior da Língua Latina. Rio de Janeiro: Livraria Acadêmica, 1958.

FIORIN, J. L.; SAVIOLI, F. P. Para entender o texto: leitura e redação. 17. ed. São Paulo: Ática, 2007.

LAKATOS, E. M.; MARCONI, M. de A. Fundamentos de metodologia científica. 6. ed. 4. reimp. São Paulo: Atlas, 2007.

LAVILLE, C.; DIONNE, J. A construção o saber: manual de metodologia de pesquisa em ciências humanas. Tradução de Heloísa Monteiro e Francisco Settineri. Porto Alegre: Artmed; Belo Horizonte: Editora da UFMG, 1999.

LEITE, M. Q. A construção da norma linguística na gramática do século XVIII. Alfa, São Paulo, v. 55, n. 2, p. 665-684, 2011. Disponível em: $<$ http://www.scielo.br/pdf/alfa/v55n2/14.pdf $>$. Acesso em: 2 jul. 2017.

MONTEAGUDO, H. A Galiza e o espaço linguístico-cultural de expressão portuguesa. In: LOBO, T.; CARNEIRO, Z.; SOLEDADE, J.; ALMEIDA, A.; RIBEIRO, S. (Org.). Rosae: linguística histórica, história das línguas e outras histórias [online]. Salvador: UFBA, 2012. p. 51-64. Disponível em: <http://books.scielo.org/id/67y3k/pdf/lobo9788523212308-06.pdf>. Acesso em: 1 jul. 2017.

MELO, P. A. G. O uso de expressões latinas como elementos de ornamentação na linguagem publicitária escrita no Português Contemporâneo. Interfaces, Guarapuava, v. 4, n. 2, p. 60-71, dez. 2013. Disponível em: $<$ http://revistas.unicentro.br/index.php/revista interfaces/article/view/2343/0>. Acesso em: 3 jul. 2017.

MORAES, R. O plágio na pesquisa acadêmica: a proliferação da desonestidade intelectual. Diálogos Possíveis, Faculdade Social a Bahia, v. 3, n. 1, p. 91-109, 2004. Disponível em: <http://www.faculdadesocial. edu.br/revistas/index.php/dialogospossiveis/article/view/191/146>. Acesso em: 30 jun. 2017.

MORESI, E. Metodologia da pesquisa. Brasília: Universidade Católica de Brasília. Pró-Reitoria de Pós-Graduação. Programa de PósGraduação Stricto Sensu em Gestão do Conhecimento e Tecnologia da Informação, 2003. Disponível em: <http://www.inf.ufes.br/ falbo/files/ MetodologiaPesquisa-Moresi2003.pdf > . Acesso em: 30 jun. 2017. 
MINAYO, M. C. de S. O desafio da pesquisa social. In: MINAYO, M. C. de S.; DESLANDES, S. F.; GOMES, R. (Org.). Pesquisa social: teoria, método e criatividade. 28. ed. Petrópolis: Vozes, 2009.

OLIVEIRA, T. S. de; MOURA, S. A. de. Indícios sociolinguísticos em compêndios de normas: uma análise a partir da obra de Infante. Revista Linguas \& Letras, Cascavel, v. 16, n. 32, p. 315-335, 2015. Disponível em: <http://e-revista.unioeste.br/index.php/linguaseletras/issue/ view/729/showToc $>$. Acesso em: 3 jul. 2017.

PÁDUA, E. M. M. Metodologia de pesquisa: abordagem teórico-prática. Campinas: Papirus, 1996.

RIBEIRO, M. L. M; SIMONETTI, F. Gramática Latina. Icaraí: LL Divulgação, 2014. v. I: Morfologia e sintaxe.

RUBIO, C. F. Padrões de concordância verbal e de alternância pronominal no português brasileiro e europeu: estudo sociolinguístico comparativo. 2012. 391f. Tese (Doutorado em Estudos Linguísticos) Universidade Estadual Paulista "Júlio de Mesquita Filho", Instituto de Biociências, Letras e Ciências Exatas, 2012. Disponível em: <https:// repositorio.unesp.br/handle/11449/100100>. Acesso em: 1 jul. 2017.

SILVA, D. M. da. Origem e desenvolvimento das idéias lingüísticas de William Labov. 2009. 138f. Dissertação (Mestrado em Letras e Linguística) - Universidade Federal de Goiás, Faculdade de Letras, 2009. Disponível em: <https://repositorio.bc.ufg.br/tede/handle/tde/2433>. Acesso em: 1 jul. 2017.

TOZONI-REIS, M. F. de C. Metodologia da pesquisa. 2. ed. Curitiba: IESDE BRASIL S. A., 2010. 